\title{
Promoting Children Potential and Social Abilities: A Qualitative Study of Nursery Assessment Practices in Malaysia
}

\author{
D.O.I-10.51201/Jusst/12476 \\ https://doi.org/10.51201/12476 \\ Nordin Mamat ${ }^{1,}$ Mazlina Che Mustafa ${ }^{1}$, Loy Chee Luen ${ }^{1}$, Abdul Rahim Hamdan ${ }^{1}$, Abdul Rahim \\ Razalli ${ }^{1}$, Abdul Talib M. Hashim ${ }^{2}$, Mohd Mahzan Awang ${ }^{3}$ \\ Department of Early Childhood Education, Faculty of Human Development, \\ Universiti Pendidikan Sultan Idris, Malaysia. \\ ${ }^{2}$ Department of Education Studies, Faculty of Human Development, \\ Universiti Pendidikan Sultan Idris, Malaysia \\ ${ }^{3}$ Faculty of Education, The National University of Malaysia
}

\begin{abstract}
This study aims toidentify the frequency of assessments at TASKA (nursery) centres and how the assessments are conducted. The study involves 20 teachers from TASKA (nurseries) who conduct early education programs for children aged birth to 4 years old. In-depth interviews were conducted with the teachers based on instruments from the early childhood care and education (ECCE) Research Project which included two main standards, an element of children's learning and assessment. There are various frequencies of each assessments for each TASKA such as two times a year; three times a year; every three months, monthly, weekly and daily. The frequencies of assessment are depending on the TASKA needs such as a reporting to other teachers when they progress. The result also shows that the observation conducted with checklist, anecdotal record, running records and portfolio. Observation records as mentioned by the teachers to monitor children development and to show the quality of the TASKA. In conclusion, the frequency of observation gives benefit to the children and for teachers' preparation and future plan for the program. The continuation of child observations carried out by parents or guardians at home can help identify the child's development more accurately.
\end{abstract}

Keyword: early childhood education, children, nursery, assessment

\section{INTRODUCTION}

The Malaysian government has taken various strategies through the implementation of policies, increased funding as well as enhanced capacity building programs towards a strong foundation for the development and expansion of early childhood care and education (ECCE). The government has further ensured that ECCE is available to all through initiatives under the National Key Result Area (NKRA), Public Private Partnership, increase access to ECCE under the NKEA, through rapid scale-up of private child care centres as well as ECCE training centres.Malaysia has made remarkable success in recognising the need for and implementing programs to establish its commitment to ECCE. Subsequent policy and funding directions and economic analyses also add to the wealth of evidence that investing in the early years makes a significant difference to the development of a nation. However, investment in the early years has been accompanied by the introduction of a more academic curriculum, reducing children's opportunities for play activity, and resulting in less time being allowed for the development of children's imagination and creativity. All these reflect the lack of focus and integration within the early childcare community in Malaysia. 


\section{PROBLEM STATEMENT AND LITERATURE REVIEW}

In order to give the young developing child an early start in life, he/she has to have life experiences that will promote development. Learning activities should be based on the needs, desires, abilities of the baby and children's background and development. Educators or teachers should provide an activity, organize physical needs in the classroom to carry out learning activities to promote positive behaviour of young children (Awang, Jindal-Snape \& Barber 2013). They also need to provide activity and teaching planning as well as the assessment activity; implementation of teaching and learning appropriate to children at nursery level (Nordin et al., 2020; Nordin et al., 2019).

\section{Young Children Play-based Assessment (TASKA)}

The curriculum of PERMATA (2013) Malaysia records pedagogy of play, and observation and evaluation of child development is appropriate and effective in the learning among children between 0-4 years old. Observations and assessments of child development are emphasized in the PERMATA curriculum to identify child's development. Proposed types of assessment (i) anecdotal records (ii) continuous records (iii) child development checklists (iv) portfolios and (v) PERMATA child logs that must be completed by parents or guardians and teachers on a daily basis. Parents have to record information about their child's condition at home while the teacher records the child's current activities in the nursery.

The literatures shown the practices of assessment method towards children's learning development, and the frequency of assessments per TASKA(nursery) centres. Berkhout, Hoekman and Goorhuis-Brouwer (2011) conducted a study on making observations on children's free play by analyzing video recordings. Data were analyzed with the help of observation instruments. Through the observation, it was found that in free play activities children show a variety of play activities that can help physical, emotional, social and cognitive development. Lin and Li (2018) conducted a study of assessment children's play activities at home that involved parents. Child's logs in which parents used giving informatic and aunthentic practice. The more parents observe children's play as a basic concept in children's development. It is found that parents believe that play can provide entertainment and fantasy to children. Ghani, Awang, Ajit \& Rani (2020) has highlighted the importance of out-of school activities in promoting soft skills among children. So, these elements should be taken into account in assessing quality of educational programs including pre-school centres and nurseries.

Bellman, Byrne and Sege (2013) conducted a study on the developmental assessment of children stated that developmental assessment refers to the process of mapping the performance of children compared to children and the frequency of assessment. Children's development is divided into (i) speech and language domains, (ii) gross and fine motor skills, (iii) Children's social and personal and (iv) performance and cognition. The frequency of observation gives benefit to the children and for teachers' preparation and future plan. The continuation of child observations carried out by parents or guardians at home can help identify the child's development more accurately.

Guddemi (2003) in the role of quality assessment in young children states that formal assessment and informal assessment bring benefits and are important for the development of infants, toddlers, nursery children and preschool children. The challenge to implement assessment is that each child is different, grows and develops rapidly and is influenced by the environment. Types of assessments suitable for children include as follow:

(a) Checklists - observations of children's behavior and skills can be recorded in a checklist using clear and relevant items.

(b) Anecdotal Records - require a short narrative description that has facts regarding the child's behavior and observed skills can be recorded in anecdotal records. The records recorded are purposeful and there are only a few sentences based on an incident.

(c) Running records - similar to anecdotal records but have more detailed notes in narrative format. Suitable for analyzing the development of social skills or behavioral problems of children and focusing on the field of learning within a period of thirty minutes. 
(d) Portfolios - collections of children's work in concrete form. Suitable for evaluating children's products, abilities, skills and knowledge.

(e) "Home inventories" - assessments of children's behavior and skills implemented by parents or guardians at home to gather information through surveys or sets of short and open answer items.

(f) Developmental screenings - examinations of a child's development and behavior according to age. This type of assessment aims to identify the level of achievement of a child's development whether it needs a more thorough diagnostic.

(g) Diagnostic assessments - aim to identify the strengths and weaknesses of the child as well as specific remedial actions for the child. This assessment is not a direct measure of academic results and should not be used for accountability purposes only.

(h) Standardized assessments, which are assessed in groups. This protocol assessment conveys normative and scaled data reported to administrators and policy makers. Assessment standards are used to monitor trends, programs and accountability in early childhood. Standard tests for children should contain authentic content and clear instructions as well as use interesting colors and graphics.

Dankiw, Tsiros, Baldock and Saravana (2020) conducted a study on the implementation of unstructured nature play for health care assessment in a child's development. Nature play is beneficial for the health and development of children, especially in terms of physical and cognitive. Nature play refers to natural elements such as trees, plants and stones bring children closer to nature. Nature games educate children to love nature and have positive effects and improve children's physical and cognitive skills.

Nah Kwi-Ok and Kwak Jung-In (2011) studied on the practice of child assessment in the context of the educational environment and early childhood care. The results of this study support early childhood educators using informal assessment techniques. Observation is the right way and is recommended by experts to know and understand the development of children. TASKA children are unable to demonstrate their knowledge and understanding through formal assessment because their language ability is limited. The main purpose of child assessment is to identify the status of the child's developmental stage. Assessment is very helpful in explaining children's achievement. The assessment to be used to inform parents or guardians of the child's development and achievement is accompanied by a comprehensive profile and portfolio of children during meetings with parents.

Johnson and Radtke (2020) stated that teachers constantly make observations on children to identify the development and achievement of children, review the learning environment, physical space, teaching aids and check the health and safety of children. Educational strategies to avoidi bullying behaviour at the early stage would be one of the important elements when assessing any school curriculum (Ghani, Jalal, Nasir \& Awang 2020). The results of the observations can help teachers to plan and implement learning activities based on curriculum, design and organize learning spaces, tracking behaviors and monitor children's social interactions throughout learning activities, establish good relationships and communicate with children's families, and assess the progress and development of the child. Observations can evaluate the effectiveness of early childhood programs; improvements in quality practice in early childhood; planning and implementing learning activities based on curriculum appropriate to the level and development of the child; measuring and evaluating child development; establishing good cultural, family and community relationships; select and use effective learning strategies; teach confidently and adhere to the ethics and standards of professional practice as an early childhood educator.

Bates, Schenck and Hoover (2019) stated that anecdotal records are authentic, formative and most useful assessments, and focus on children's development, skills and knowledge. Anecdotal records are practical strategies for taking meaningful notes for children. Teachers make close and periodic observations every day or weekly observation. Observations on children's behavior and development should be recorded and documented so as not to forget what has been observed. Organizing and managing anecdotal records using index cards, post-it notebooks and bookmarks. The study of Akers, AtkinsBurnett, Monahan, Chart, Wasik and Boller (2015) used continuous assessment to identify child achievement and developmental levels. These practices can achieve better learning outcomes through 
learning activities, tracking children's progress, providing more effective instruction, identifying children's strengths, needs, and interests, helping vulnerable children. Assessment data can be used to guide children in terms of behavior, development and achievement in skills and knowledge to identify children's performance and progress.

Based on the evidents and recommendations above, this current study seeks to explore the assessment practices towards children's learning activity. The research questions of this study is what is the frequency of assessments at TASKA(nursery) centres? How is the assessment conducted?

\section{METHODOLOGY}

A qualitative methodology was used in this study because it is considered to be the most appropriate way of discovering about assessment practices towards children's learning activity (Nordin et al, 2019). The study involved 20 teachers from TASKA (nurseries) that conduct early education programs for children aged birth to 4 years. This methodology was applied to explore the assessment practices and the frequency of assessments TASKA(nursery) centres. In-depth interviews were conducted with the teachers based on instruments from the ECCE Research Project which included two main standards, an element of children's learning and meaningful learning. Interview data was transcribed from the audio recordings and then analysed using the n-vivo applications. Relationships between the axial nodes were scrutinised to narrow them down into major themes. Each transcript underwent pair-comparison, then each group presented their own mapping in the group comparisons sessions and finally, the mapping for each group was drabbed based on factors that contribute to quality teaching and learning.

\section{FINDINGS}

In TASKA, assessments were conducted to evaluate and improve children's ability and performance. This study is to identify the frequency of assessments per TASKA(nursery) centres and how the assessments are conducted. The frequency of each rating for each TASKA varies, it can be two times a year; three times a year; every three months, monthly, weekly and daily. The frequency of assessment of each TASKA is as follows:

(a) Two times a year and Three times a year

According to the teachers from TASKA KEMAS they said:

R2: It is done twice a year in June and October. 2 times, in June and November. New PERMATA $Q$ wants to do it this year

R4: June and October: 2 times (IV.15 GI KEMAS KEDAH SUPERVISOR 01)

From the industry expert, TASKA did assessment formally, twice a year.

Yes, usually we do after in the middle of the year, and one, the final one is at the end of the year. Because they are going to move on to another year, the class. Or another school, then the parents have the reports to bring to another centre. Or we pass it up to another teacher, because the child is going to level up and up (III.22 ID INDUS EXPERT 020).

In order to carry out assessment on children, for me, it's better at the end of the year, because, at the beginning of the year, we can't see anything yet. Because at TASKA, we have two semesters; first semester, and second semester. So, that first semester, let's give her something she likes first. And then, when the second semester comes, we get the results, right? (That's it), we always focus more towards the end of the year for the right assessment (VI.2.04 O. F4.08_PRIVATE.TS.12).

Some TASKA conducted the assessment three time a year and using PERMATA $Q$ and National Child Data Centre:

R1: It is done in April, July and September. So, the teacher has to do it regarding the 4M. So, the teacher got to do it three times a year. The teacher no need to fill it in for May other than stated. R5: If it's TABIKA, then it will follow April, July and September. 
R3: Three months. It's three months along with the NCDC but for reporting to send it to the state, it is twice. As for what is asked of us in the classroom, it's three months (IV.13 GI PRIVATE TASKA JOHOR SUPERVISOR 02)

R1: So that he can remember, so he knows two people. But besides looking at other kids. So he's going to make an observation note. Ok that assessment comes in at the end of the month, so the first three months of that phase we will see the development. Let's give it three categories. Not only do we want to improve the child, we want to see the quality of the child too. So let's focus on what the techniques are for this second phase, how else for the children to develop, to excel. (IV.16 GI PRIVATE TASKA SABAH SUPERVISOR 07)

TASKA as private school, I am doing the monitoring. The KPM has two TASKA, and for the operators we will appoint someone from outside. We provide the place and facilities. We give the children of the staff here; we appoint an outside operator to handle this TASKA. We pay him from the private. As for the monitoring of the organisation, if I am not mistaken, it is 3 times a year (III.17 ID PERMATA HQ 17)

In those three months, it is okay to monitor because well, the orientation phase is over. After two months, the children will start studying. The monitoring depends on the children's level. Which means, the questions cannot be the same. Phase one with chechlist...the question may be simpler. Then the second one would be a little difficult with portfolio. And finally it will be difficult, we will follow KSPK (IV.14 GI KEMAS JOHOR Teacher)

(b) Every 3 months

Usually around every three months (VI.2.01 O.F4.02_JPNIN.TS.T.13)

Every three months (VI.2.08 O.F4.23_PRIVATE.TS.T.11)

Every three months. Then we have to do some observations. Observe the achievement of the children. That's it. Whether they can master it, on progress to mastering it or not yet mastering it. So if the children haven't mastered it yet, the TASKA teaches will help the children where they still need help. So that's one of the following actions. Because the children also have the learning criteria that they have to pass. So if the children can't master it, the teacher will see which side, which chapter the teacher should help. And the teacher will come back with a record. That anecdotal record. Observation records (III.20 ID EDU IPG TAWAU)

As for the observation, it happens (in the classroom) for as long as the teacher takes note. (IV.6 GI PERTIM OPERATOR 06)

(c) Monthly

The observation is done monthly.

R3: What we call a progress book for how many days of the month are we going to send it to the supervisor to formulate a subject like that I mentioned earlier and the subjects and pq that are the evaluation by the month ... here the supervisor will formulate a presentation for the meeting. That is more to the teacher the teacher who should strive for his son next month should make sure that he can ...that he will try his best .. but if the boy's achievement is the same then...in case it will not be so many there are two people who can't do it but the teacher will try his best to bring her as much as she can though no amount of pounds (IV.2 GI YIT SUPERVISOR 002)

(d) Daily

These assessments, on a daily or weekly basis, depend on the child's circumstances and needs.

Sometimes I monitor everyday. When the children learn, we can see. Sometimes for a month when they still in tears, then it is usually half a month later they can talk, they can scream and all (VI.2.01 O.F4.02_JPNIN.TS.T.13)

Often, like when it's time to go home, the teacher will tell her parents. When their kid has problems. These days .. the days are going to be written in the SMS book, to let your parents know. So, they teacher will remind the parents (VI.2.03 O.F4.06_KEMAS.TS.T.10)

Every day Odah will look at the development of each child. Odah really wants to know the development of the children, for example like language, emotional, spiritual, taking turns and 
sharing toys, Odah will give the child a toy and Odah will see whether this child can share it or not (VI.2.08 O.F4.23_PRIVATE.TS.T.11)

(e) Weekly

It is conducted weekly.

But informally, all the time. So in the weekly evaluation of what is happening in the classroom, they will write. Maybe they will write about this particular child, especially if the child got problems. Or if there was a breakthrough and the child said a word if they never spoke before. Or you know, they discover that children have a very keen interest in something, like planets and they know so much about planets. They'll write it down.

R: Yes. Weekly. And then when I read their record, I know what's going on in the classroom and I know the child. And I am also going to observe. So when I talk to the child, I know what to talk to the child about and to their parents also. So the parents will get the feedback from me as well. Or sometimes they will get it from the teachers, because from outside they have to walk the child in. They always talked and had a chat with teachers (III.22 ID INDUS EXPERT 019)

\section{DISCUSSION AND CONCLUSION}

This study aims to identify the frequency of assessments per TASKA(nursery) centres and how the assessments are conducted.

\section{Frequency of Assessment}

Teachers also imply that assessment practices are aligned with the frequency of conducting it. These also will rate the efficiency of assessment process. There are various frequencies of each rating for each TASKA such as two times a year; three times a year; every three months, monthly, weekly and daily. The frequency of assessment of each TASKA is as follows; the frequencies of assessment are depending on the TASKA needs. Some of the TASKA do the assessment twice a year which is in the middle of the year, and the second one is at the end of the year. It is for the preparation of the children to move on to another year or to another school, which the parents need the reports to pass it to. And it also as a reporting to other teachers when they progress to another class. In order to carry out assessment on children, the teachers feel that the assessment should be conducted at the end of semester, because in TASKA, they have two semesters; first semester and second semester. In the first semester, we enlightened the children and in the second semester comes, we get the results.

According to the teachers there are TASKA which conducted assessment every quarter of the year but reporting to NCDC twice a year. There also TASKA which conducted assessment in every three months in order to ensure the children's progress being monitored. As reported, they also do a montly, weekly and daily assessment by observation looking to the children immediate progress, this to ensure that the children will have a prompt help and action.

\section{Assessment practices in TASKA}

Based on the findings, it shows that how the observation conducted with checklist, anecdotal record, running records and portfolio. Observation records as mentioned by the teachers are to monitor children's development and to show the quality of the TASKA. The instrument will indicate children's skills and reporting the children's progress through observation, class assessment and children activities. In the teachers' perspective, information of parents should also be included in the instrument. These will enable teachers to have a good rapport with parents. Scores and details of children's ability will indicate the children's development, and which measures to be adopted in helping children's development with the involvement of parents. Furthermore, parents' details and information are important due to connectivity and interactions. Teachers can discuss and plan necessary actions with parent in helping children to be nurtured accordingly without any biased. These practices shows that, reporting is a very important in children developing progress through observation and assessment. Therefore, mode of assessment used by TASKA whether developed by Permata-Q or NCDC is a necessary tool to be adopted. Teachers views are inline with Strand, Cerna and Kucy (2007), which suggested that through the assessment of more 
information on the development, strength and ability of children in the domains of language and literacy, mathematics and science, social and emotional, creative, physical and health arts are obtained to produce a variety of effective interventions for children, to aid the overall development of the child.

\section{CONCLUSION}

In conclusion, the frequency of assessment practices and how the instruments used to assess children's ability are inevitable. Good practices of assessment adopted and with the quality of instrument used will ensure the development of children are in the right path. The developmental assessment refers to the process of mapping the performance of children and the frequency of the assessment. The frequency of observation gives benefit to the children and for the teachers' preparation and future plan for the program. The continuation of child observations carried out by parents or guardians at home can help to identify the child's development more accurately.

\section{ACKNOWLEDGEMENT}

This part of the research "Development of a comprehensive and integrated model of quality Malaysian early childhood care and education-project 3/TLAA: determining contributing factors of quality ecce" (2015-0024-106-04-3) is funded by the Ministry of Finance through the Malaysian Ministry of Education. Special appreciation is also dedicated to the National Child Development Research Centre, Universiti Pendidikan Sultan Idris, Malaysia for giving us the opportunity to carry out this research project.

\section{REFERENCES:}

Akers, L., Atkins-Burnett, S., Monahan, S., Carta, J., Wasik, B.A. \& Boller, K. (2015). What does it mean to use ongoing assessment to individualize instruction in early childhood? Early Childhood Teachers' Use of Ongoing Child Assessment to Individualize Instruction, 2015 (61), 1-8.

Awang, M.M., Jindal-Snape, J.\& Barber, T. 2013. A Documentary Analysis of the Government's Circulars on Positive Behavior Enhancement Strategies. Asian Social Science, 9 (5), 203-208

Bates, C. C., Schenck, S.M. \& Hoover, H.J. (2019). Anecdotal records: Practical strategies for taking meaningful notes. Young Children, 74(3), 14-19.

Bellman, M., Byrne, O. \& Sege, R. (2013). Developmental assessment of children. Clinical Review, BMJ 2013, 1-9.

Berkhout, L., Hoekman, J. \& Goorhuis-Brouwer, S.M. (2011). Observing free play in classrooms with an instrument based on video analysis, Early Child Development and Care,182 (5), 125-136.

Dankiw, K.A., Tsiros, M.D., Baldock, K.L. \&Saravana Kumar. (2020). The impacts of unstructured nature play on health in early childhood development: A systematic review. PLoS ONE 15, (2), 1-22.

Fesseha, E., \& Pyle, A. (2016). Conceptualizing play-based learning from the kindergarten teacher's perspective. International Journal of Early Years Education, 24(3), 361-377.

Ghani S.A., Jalal B., Nasir A.Q.A., Awang M.M. (2020).School Bullying in Southeast Asia Countries:Catagories, Elements and Incidences. International Journal of Psychosocial Rehabilitation, 24(01), 5342-5350

Ghani S.A., Awang M.M., Ajit G., Rani M.A.M. (2020). Participation in Co-Curriculum Activities and Students' Leadership Skills. Journal of Southwest Jiantong University,55(4), pp 5342-5350

Guddemi, M. P. (2003). The important role of quality assessment in young children ages 3-8. In Wall, J. \& Walz, G. (Eds.) (2003). Measuring up: Assessment issues for teachers, counselors, and administrators. Greensboro, NC: ERIC Counseling and Student Services Clearinghouse.

Johnson, A. \& Radtke, T. (2020). Observation and assessment in early childhood education. United States: California Community Colleges.

Lin Xunyi \& Li Hui. (2018). Parents' play beliefs and engagement in young children's play at home, European Early Childhood Education Research Journal, 26:2, 161-176. 
Nordin Mamat, Loy Chee Luen, Nor Mashitah Mohd Radzi, Sopia Md Yassin \& Syahida Iryani Mohd Yusoff. (2018). Reliability, Validity and Fairness of Interviews for Teaching and Learning Project in Quality Early Childhood Care and Education: Preliminary Study. International Journal of Academic Research in Business and Social Sciences. 8(6), 1283-1292.

Nordin Mamat, Loy Chee Luen, Mazlina Che Mustapha, Abdul Rahim Razalli, Abdul Talib M. Hashim \& Ramlee Ismail. (2019). The Quality of PERPADUAN Pre-school Environment and Human Resources: Teachers' Satisfaction on their Career Development. International Journal of Academic Research in Business and Social Sciences 9(5), 882-897.

Mamat, N. Isha, S.R., Asong, R., Awang. M.M. \& Ahmad, A. R 2020). Interactive multimedia technology for improving child's languange learning, Shanghai Ligong Daxue Xuebao/Journal of University of Shanghai for Science and Technology. 22(11).1000-1006.

Nah Kwi-Ok \& Kwak Jung-In. (2011). Child assessment in early childhood education and care settings in South Korea. Asian Social Science, 7 (6), 66-78.

PERMATA. (2013). Kurikulum PERMATA Negara. Cyberjaya: Bahagian Pendidikan Awal Kanak-kanak (PERMATA), Jabatan Perdana Menteri, Malaysia.

Strand, P. S., Cerna, S. \& Skucy, J. (2007). Assessment and decision making in early childhood education and intervention. Journal of Child and Family Studies, 15(6), 671-680.

Velickovic, S. (2013). Children's portfolio work for monitoring the development and promotion of preschool children. Russia, Rostov-na-Donu, February 2013, 305-313. 